\title{
Lead concentrations in whole blood, serum, saliva and house dust in samples collected at two time points (12 months apart) in Santo Amaro, BA, Brazil
}

\author{
Carolina de Souza Guerra ${ }^{a, j}$, Gustavo Alonso Muñoz Magna ${ }^{b, j}$, Sandro Lemos Machado ${ }^{b, j}$, \\ Eduardo Mello De Capitani ${ }^{c, j}$, Junia Ramos ${ }^{\mathrm{d}, \mathrm{j}}$, Iza Teixeira Alves Peixoto ${ }^{\mathrm{a}, \mathrm{j}}$, \\ Aníbal Araujo Alves Peixoto ${ }^{e, j}$, Maria Lucia Vieira Moreno ${ }^{f, j}$, Juan Carlos Rossi Alva ${ }^{g, j}$, \\ Flávio Venâncio Nakadi ${ }^{\text {h,j }}$, Márcia Andreia Mesquita Silva da Veiga ${ }^{\text {h,j }}$, \\ Fernando Barbosa $\mathrm{Jr}^{\mathrm{i}, \mathrm{j}}$, Raquel Fernanda Gerlach ${ }^{\mathrm{d}, \mathrm{j}, *}$, Miriam de Fátima Carvalho ${ }^{\mathrm{h}, \mathrm{j}, \text {,*** }}$ \\ a Department of Morphology, State University of Campinas (FOP/UNICAMP), Piracicaba, SP, Brazil \\ ${ }^{\mathrm{b}}$ Department of Science and Technology of Materials, Federal University of Bahia (UFBA), Salvador, BA, Brazil \\ ' Department of Internal Medicine, Poison Control Center, Faculty of Medical Sciences, State University of Campinas (UNICAMP), Campinas, SP, Brazil \\ ${ }^{\mathrm{d}}$ Department of Morphology, Physiology and Basic Pathology, Dental School of Ribeirao Preto, University of Sao Paulo (FORP/USP), Ribeirao Preto, SP, Brazil \\ e Private Pediatrician that Works in Santo Amaro, BA, Brazil \\ ${ }^{\mathrm{f}}$ Instituto Gonçalo Moniz, Fundaçao Osvaldo Cruz (FIOCRUZ), Salvador, BA, Brazil \\ ${ }^{\mathrm{g}}$ Institute of Biological Sciences, Catholic University of Salvador (UCSAL), Salvador, BA, Brazil \\ h Departamento de Química, Faculdade de Filosofia, Ciências e Letras de Ribeirão Preto, University of Sao Paulo (FFCLRP/USP), Ribeirao Preto, SP, Brazil \\ i Department of Clinical, Toxicological and Bromatological Analysis, Faculty of Pharmacy of Ribeirao Preto, University of Sao Paulo (FCFRP/USP), Ribeirao \\ Preto, SP, Brazil \\ ${ }^{j}$ School of Engineering, Catholic University of Salvador(UCSAL), Salvador, BA, Brazil
}

\section{A R T I C L E I N F O}

\section{Article history:}

Received 30 June 2014

Received in revised form 25 May 2015

Accepted 27 May 2015

Available online 18 July 2015

\section{Keywords:}

Lead

Blood

House dust

Serum

Saliva

Santo Amaro

Lead smelter

\section{A B S T R A C T}

Whole Blood Lead Level (BLL) is the main marker used to verify lead contamination. The present study explores how BLL is associated with lead concentrations in serum, saliva and house dust. Samples were collected twice from Santo Amaro, BA, Brazil, a region that was contaminated by a lead smelter in the past; a time interval of 12 months was allowed between the two collections. It is noteworthy that the following measures have recently been taken to diminish exposure of the population to lead: streets have been paved with asphalt, and educational campaigns have been launched to reduce exposure to contaminated dust.

Results: Compared with the first time point, all the samples collected at the second time point contained lower lead concentration $(p<0.05)$, which suggested that the adopted measures effectively reduced exposure of the population to lead present in contaminated soil and dust. Statistically significant correlations only existed between lead in blood collected in the first year and lead in blood collected in the second year (Spearman's $r=0.55 ; p<0.0001 ; n=62$ ), and lead in house dust collected in the first year and lead in house dust collected in the second year (Spearman's $r=0.5 ; p<0.0001 ; n=59$ ).

Conclusions: Results support the validity of lead determination in blood and in house dust to assess lead exposure over time. However, lead in blood and lead in dust did not correlate with lead in serum or lead in saliva.

(c) 2015 Elsevier Inc. All rights reserved.

\footnotetext{
* Correspondence to: CEP: 14040-904 Monte Alegre, Ribeirão Preto, SP, Brazil. Fax: +55163602 4102.

** Correspondence to: Pinto de Aguiar no. 2589, Pituaçu, Salvador, BA, Brazil.

E-mail addresses: rfgerlach@forp.usp.br (R.F. Gerlach), miriam@ucsal.br (M. de Fátima Carvalho).
}

\section{Introduction}

Lead is a well-known toxic metal that is usually associated with the enormous burden of social, financial, and medical/psychological issues faced by the population living in areas where it is or was smelted (Warren, 2000; Denworth, 2009; Markowitz and Rosner, 2013).

Blood lead levels are the golden standard to determine present 
exposure to lead. In children and adolescents, blood lead levels can partly reflect the current exposure and partly represent the endogenous exposure to lead stored in bone, which undergoes constant remodeling during growth (Barbosa et al., 2005). Therefore, albeit still exploratory, comparison of blood lead levels with other markers is interesting. For instance, Rezende et al. (2010) have reported correlations of lead in plasma and in serum. Costa de Almeida et al. (2009a) have also investigated the association between lead in saliva (a filtrate from plasma) and the degree of environmental pollution. Furthermore, to distinguish between past and current exposure, it is important to obtain the levels of lead in house dust. The impact of dust as a contributor to lead contamination in children is well known and has been recently discussed by Yoshinaga et al. (2014).

Santo Amaro, a town in the Brazilian state of Bahia, has 57,800 inhabitants (2010 census) and a human developmental index for municipalities of 0.646, according to IBGE, the Brazilian Institute of Geography and Statistics (BRASIL, 2014). A lead smelter operating from 1956 to 1993 contaminated this city (Carvalho et al., 2003; Machado et al., 2013). This company was a subsidiary of a French company (Penarroya Oxide) and was initially called COBRAC; its name was changed to PLUMBUM Co in the last years of operation. The same company also operated a plant in the Ribeira River Valley, on the border between the states of Sao Paulo and Paraná, in a city called Adrianópolis (PR). Reports of chronic environmental lead exposure also exist in the Ribeira River Valley (Paoliello et al., 2002). These two lead smelter sites are the ones with the highest levels of environmental lead contamination reported so far in Brazil (Paoliello and De Capitani, 2007). Reports on chronic lead contamination in the work place also exist, especially in connection with lead battery recycling plants (Paoliello and De Capitani, 2007). Indeed, some of these battery recycling plants do not rely on proper environmental control measures, and reports about the contamination of the population in the surroundings exist (De Freitas et al., 2007; Costa de Almeida et al., 2007; de Almeida et al., 2008).

The lead company plant operating in Santo Amaro, BA, was located $3 \mathrm{~km}$ away from the city center, on Rui Barbosa Avenue. The chimney of the former plant still exists, and it is $80 \mathrm{~m}$ high (Fig. 1). The plant was destroyed, and the lead slag was encapsulated in 2000. However, in the 1990s, the lead slag had been used to pave streets; the slag had also been used as landfill throughout the town; particularly, the entire Rui Barbosa Street was paved using slag (where the study population lives). Together, these facts worsened lead contamination within the community Many authors have investigated this contamination as well as the ineffective handling of this issue by public authorities (Andrade and Moraes, 2013).

According to Machado et al. (2013) analysis performed in 223 superficial soil samples from Rui Barbosa Street, in the metallurgy neighborhood, indicated that approximately $80 \%$ of them presented values above the lead limits established by CONAMA No. 420/2009 (Brazilian Resolution on soil elements accepted limits) for residential areas $(300 \mathrm{mg} / \mathrm{kg}$ ). It was also observed that $50 \%$ of the samples had concentrations above the limit set for industrial areas $(900 \mathrm{mg} / \mathrm{kg}$ ). For cadmium, $26.6 \%$ of samples presented values above the agricultural investigation limit ( $3 \mathrm{mg} / \mathrm{kg}$ ), and $11.7 \%$ of the samples presented values above the residential investigation limit $(8 \mathrm{mg} / \mathrm{kg})$. Furthermore, the residue is typically composed of 3 to $4 \%$ by weight lead oxide ( $\mathrm{PbO}$ ), classified according to NBR 10004/2009 as a dangerous material (Anjos, 1998; Machado et al., 2004). Regarding lead in dust, Oliveira (2010) made a study on the dust concentrated in air conditioners. This study suggests that the amount of lead in dust is more related to heavy traffic than to distance to the former metallurgy. It also suggests that the slag might be the reason why high lead levels in dust are found throughout the city.

In recent years, efforts have been made to mitigate the effects of this contamination and even reduce lead levels in the environment. In 2010 (the first year of sample collection), digging was conducted on Rui Barbosa Avenue, to change the pipes in preparation for street paving with asphalt; paving occurred in 2011. Many scientists and health and environmental sciences experts have made suggestions on how to mitigate the contamination and reduce exposure. Paving back and front yards and repaving the streets to cover the slag were some of such measures. In 2013, the Brazilian Federal Justice Attorney required that the former companies clean the environment and pay compensations for the health problems caused to former employees (Environmental Justice Atlas: ejatras.org/conflict/lead-contamination-insanto-amaro-bahia-brazil).

The aim of this study was to determine lead concentrations in whole blood, serum, saliva, and house dust at two time points (12 months apart), to find out whether these markers are associated, and to assess the effectiveness of the remediation measures taken by the authorities in recent years.

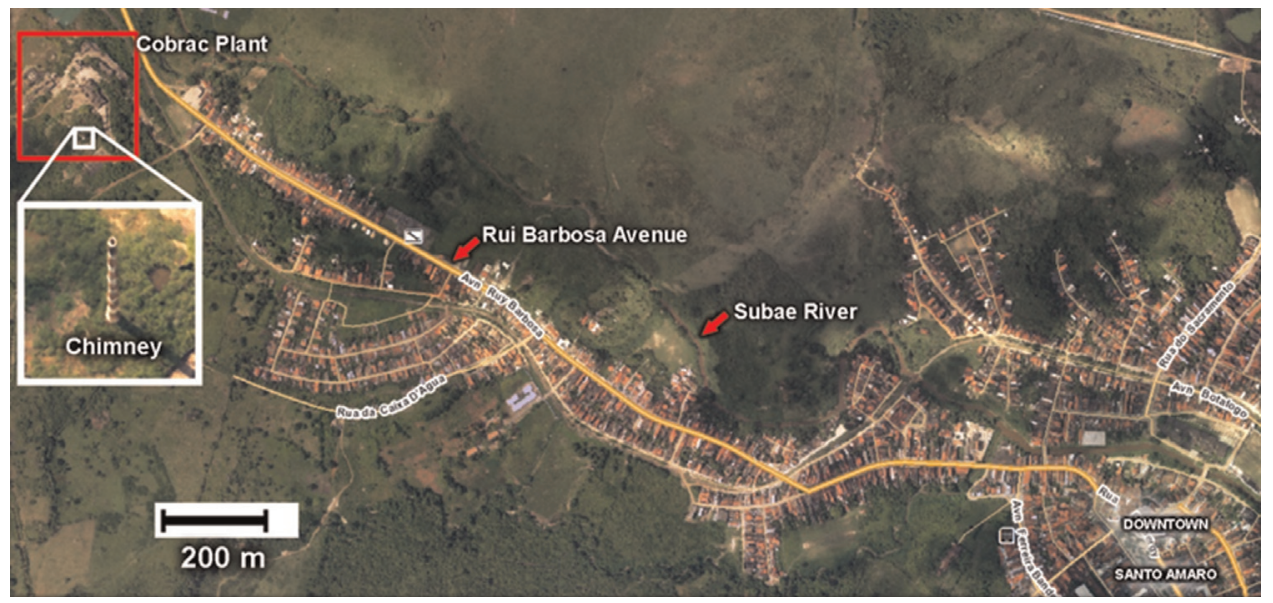

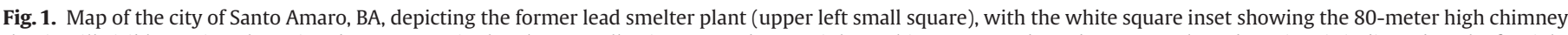

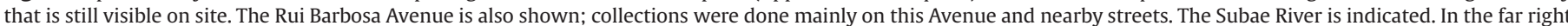
low corner is downtown Santo Amaro. Scale $=200 \mathrm{~m}$. 


\section{Materials and methods}

\subsection{Study population}

This study protocol was approved by two Ethics Committees on Human Research (one in the State of Sao Paulo and one in the State of Bahia), subject to Resolution 196/96 of the National Commission of Ethics in Research. The parents or a guardian signed an informed consent form prior to inclusion of the child in the study.

In 2010, the study population included 99 children and adolescents. In 2011, the sample consisted of 75 children and adolescents, who had also been part of the group analyzed in 2010 . The samples were taken in October 2010 and October 2011.

All the children lived in homes located close to the former lead smelter plant $(<2 \mathrm{~km})$, most homes were located on the Rui Barbosa Avenue, in the urban area of Santo Amaro, BA (Fig. 1). Researchers visited the families and explained the purposes of the study; the informed consent was obtained from the parents/ guardians, who signed the consent and subsequently answered a questionnaire about their child's habits. On a later date, the researchers visited the houses again and collected blood and dust samples.

Information on pavement of the Rui Barbosa Street, years of residency in the house, use of slag in the yard etc had been collected in 2009 by a group that studies lead in soil, and residents of the entire Rui Barbosa Street were visited. On this street, 34/63 lots (54\%) had slag used in their yards (as informed by the residents). Twenty eight \% of the residents did not know this information. None of the houses included in this study had their yard cemented (to incapsulate the slag). This measure is slowly being adopted in the town, but in 2010 only 40/274 yards had been cemented (corresponding to $14.5 \%$ ) (Rabelo, 2010).

\subsection{Materials}

Milli-Q water (resistivity $18.2 \mathrm{M} \Omega \mathrm{cm}$ ) (Milli-pore, Bedford, MA, USA) was used throughout the study. All the reagents were high-purity analytical grade. All the materials were washed in nitric acid-transfer pipettes, centrifuge tubes, plastic bottles, autosampler cups, and glassware materials were soaked in $10 \% \mathrm{v} / \mathrm{v}$ $\mathrm{HNO}_{3}$ for $24 \mathrm{~h}$, followed by rinsing (five times) with Milli-Q water and drying on a laminar flow hood. All nitric acid used for analysis was double-destilled nitric acid.

\subsection{Sample collection}

\subsubsection{Whole blood and serum}

Before blood collection, the skin of the child was cleaned with $70 \%$ ethanol. Venous blood samples were collected in two 6-mL evacuated tubes. The first tube contained EDTA, for whole blood lead determination (TraceMetal Free EDTA Tube, Dark Blue Cap, Vacutainer BD, Becton-Dickinson, Brazil), and the second tube was ideal for serum collection (Trace Element Serum, plain/no preservative, Ref. 368380, Royal Blue Cap, Vacutainer, BD). Samples employed to measure $\mathrm{Pb}$-serum were centrifuged between 1 and $4 \mathrm{~h}$ of sample collection (at $800 \mathrm{~g}$ for $6 \mathrm{~min}$ at room temperature). The serum fractions were then pipetted into an ultraclean centrifuge tube $(2 \mathrm{~mL})$. All the samples were kept at $-20^{\circ} \mathrm{C}$ until lead determination. At the time of analysis, the serum samples were examined with the naked eye, to observe the degree of hemolysis. In some samples, this occurred at separation. Slightly discolored samples were excluded from this study.

\subsubsection{Saliva}

Unstimulated saliva was collected by asking the child to spit for 5 minutes into a $50 \mathrm{~mL}$ Falcon Tube, which was later centrifuged to pellet and avoid cell and food debris. The mouth had been cleaned with tooth brushing before collection. A tooth brush and a tooth paste was distributed to the children, and the brushing was carried out by a pedodontist (C.S.G.) in children under 6 years of age. Small children that were unable to spit had their saliva collected by using a plastic Pasteur pipette that had been cleaned as described above.

\subsubsection{Sample centrifugation and storage}

Serum and saliva samples were transported from the collection to a lab, where they were centrifuged and the supernatant was stored in the refrigerator.

\subsubsection{House dust}

Dust was collected from three sites in each home, using a baby wipe that had been previously cleaned in the same way as described above for all the other materials (wipes were soaked in $\mathrm{HNO}_{3}$ overnight, washed in 5 changes of MilliQ water, and dried in a Class 100 hood). The collection method followed the NIOSH protocol for performing spot tests on wipes. Three wipes were collected in separate rooms of each home (bedroom, living room, and kitchen). A $0.3 \times 0.3 \mathrm{~m}^{2}$ square area was defined with tape on the floor for dust collection with the wipes. Collection was done using "S" shape movement.

Prior to analysis, the wipes were digested using a microwave reaction system (Microwave 3000, Anton Paar, Ashland, VA, USA). Glass tubes were cleaned by immersion in nitric acid and copious washing in MilliQ water, as stated for all materials.

Two hundred milligrams of wipe cut into pieces was inserted into the glass tubes with $7 \mathrm{~mL}$ double-distilled $\mathrm{HNO}_{3}$ plus $1 \mathrm{~mL}$ $\mathrm{H}_{2} \mathrm{O}_{2}$ (Supra Pure from Merck). Complete digestion was obtained using a program with a hold of $11 \mathrm{~min}$ at $250{ }^{\circ} \mathrm{C}$, then a hold of $5 \mathrm{~min}$ at $450^{\circ} \mathrm{C}$, and the final hold of $5 \mathrm{~min}$ at $600{ }^{\circ} \mathrm{C}$ (holds were preceded by a 5 minutes-ramp and a 1 min exhaust). Thereafter samples were diluted with the Magnesium matrix modifier $\left(\mathrm{Mg}\left(\mathrm{NO}_{2}\right)_{2} \cdot 5 \mathrm{H}_{2} \mathrm{O}\right.$ prepared in $\left.17 \% \mathrm{HNO}_{3}(\mathrm{v} / \mathrm{v})\right)$ and the Palladium modifier $\left(\mathrm{Pd}\left(\mathrm{NO}_{2}\right)_{2}\right.$ in $5 \% \mathrm{HNO}_{3}(\mathrm{v} / \mathrm{v})$ prepared as follows: $100 \mathrm{uL}$ of the Magnesium matrix modifier $+1000 \mathrm{uL}$ of the Palladium modifier and water to $10 \mathrm{~mL}$. Samples were then analyzed for lead by Graphite Furnace Atomic Absorption Spectrometry (GFAAS) (AAnalyst 600, Perkin-Elmer, USA) in the Department of Morphology, Physiology, and Basic Pathology at the Faculty of Dentistry of Ribeirao Preto, University of Sao Paulo, Campus of Ribeirao Preto (FORP-USP).

\subsection{Chemical analyses}

All the samples were stored and analyzed together at the end of the study. Lead levels in whole blood and dust were measured by GFAAS (AAnalyst 600, Perkin-Elmer, USA) in the Department of Morphology, Physiology, and Basic Pathology at the Faculty of Dentistry of Ribeirao Preto, University of Sao Paulo, Campus of Ribeirao Preto (FORP-USP). Lead in blood was measured according to the method described by Parsons and Slavin (1993). Method detection limit for lead in blood by GFAAS measurements (s3) was based on the analysis of 10 base blood samples (SRM 955c level 1) and taking in account $1+9$ dilution factor.

Lead levels in serum and saliva were determined at the Laboratory of Metals Toxicology, Faculty of Pharmaceutical Sciences of Ribeirao Preto, University of Sao Paulo, in Ribeirao Preto (FCFRPUSP), by Inductively Coupled Plasma-Mass Spectrometry (ICP-MS) (Perkin-Elmer Elan DRC II). The detection limit for lead was $1.0 \mu \mathrm{g} /$ $\mathrm{dL}, 0.01$ and $0.02 \mu \mathrm{g} / \mathrm{L}$ for whole blood, serum and saliva, respectively.

The reference materials were diluted and processed in the same way as the samples; it was assayed after every ten samples. 
NIST (Standard Reference Material) 955c Lead in Caprine Blood was used in this study when running blood samples, particularly the two lower standards, with $0.424 \mu \mathrm{g} / \mathrm{dL}$ and $13.95 \mu \mathrm{g} \mathrm{Pb} / \mathrm{dL}$ of blood. For lead in dust, the reference material used was NIST SRM 2586-Trace Elements in Soil Containing Lead from Paint (containing $432 \pm 71 \mathrm{mg} / \mathrm{kg}$ ), with a dilution that resulted in a $10 \mathrm{mg}$ amount/sample. The calibration curves were prepared with a lead solution in water $(1000 \mathrm{mg} / \mathrm{L})$ from Merck.

\subsection{Educational measures aimed at reducing exposure to lead}

One week prior to the collections, during the interview with the families and the collection of the informed consent, measures to reduce lead in the house and yard environment were discussed with the families, and given to them in writing. Those were among others: the need to reduce the opportunity of the children to play with soil (and try to completely avoid this), the need to reduce dust in the housed by cleaning surfaces of furniture and floors with a wet wipe several times a week, and the need to wash hands and change towels often.

\subsection{Statistical analysis}

The distribution of all the continuous variables was analyzed for normality, to select the appropriate statistical method. Correlations between $\mathrm{Pb}$-blood, $\mathrm{Pb}$-serum, $\mathrm{Pb}$-saliva, and $\mathrm{Pb}$-dust were tested using Spearman's correlation. A probability level of $5 \%$ was considered statistically significant for comparisons between the results for each variable obtained in 2010 and 2011. Correlations between the lead in different fluids and dust collected in 2010 and 2011 were considered significant after Bonferroni correction was applied ( 0.05 divided by the number of comparisons: 18 that are biologically and toxicologically relevant). Statistical analyses were performed using the Graph Pad Prism (Version 3.0).

\section{Results}

Table 1 lists data on the sample size collected in each year, the medians, the 25th percentile, the 75th percentile, the minimum and maximum values, the mean, CI95\%, and standard deviations, and the normality test results. This study started with 99 children aged from two to 16 years, but it was not possible to collect all the types of samples (whole blood, serum and saliva) from every child. The mean age of the children at the start of the study was eight years and 7 months. In 2010, 52 boys and 47 girls participated in this study.

Fig. 2 contains a graphical comparison of all the values of lead in blood (blood lead levels, BLL) for samples collected in 2010 $(n=99)$ and $2011(n=67)$. Comparison of the results obtained in 2010 with results achieved in 2011 (12 months later) indicated

\section{BLL in samples collected in Santo Amaro, BA, in 2010 and 2011}

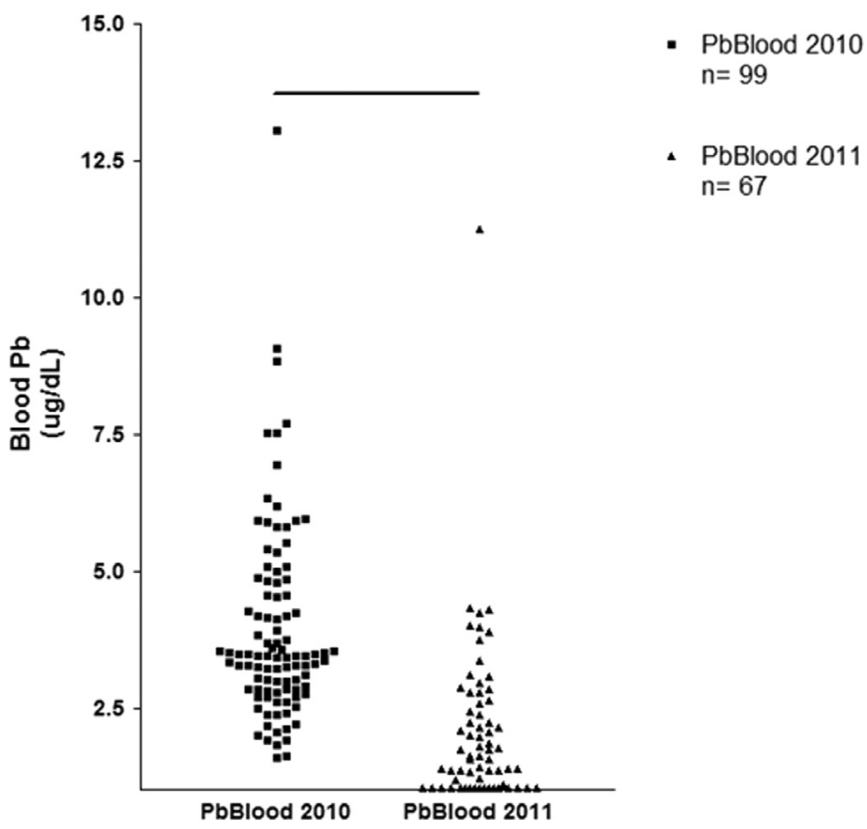

Fig. 2. Blood lead levels (BLL) expressed as $\mu \mathrm{g} / \mathrm{dL}$ found in samples collected in $2010(n=99)$ and 1 year later $(n=67)$. Values from 2011 are significantly lower than the values observed in 2010. ${ }^{*} p<0.0001$, Mann-Whitney test.

that lead concentrations decreased significantly in the children that participated in this study $(p<0.0001$, Mann-Whitney test). The difference remained statistically significant when only the 62 paired values were assessed; that is, the values obtained for samples collected from the same participant in both time points. Medians (Q1; Q3, and $n$ ) for the 2010 samples were $3.4 \mu \mathrm{g} / \mathrm{dL}(2.8$; 4.7, $n=99)$ and $3.4 \mu \mathrm{g} / \mathrm{dL}(2.8 ; 4.7, n=62)$. For the 2011 samples, medians (Q1; Q3, and $n$ ) were $1.04 \mu \mathrm{g} / \mathrm{dL}(1.04 ; 2.7, n=67)$ and $1.04 \mu \mathrm{g} / \mathrm{dL}(1.042 .7, n=62)$, showing that dropout did not underlie the observed reduction in whole blood lead concentrations.

Fig. 3 displays the values of lead in serum for samples collected in Santo Amaro, BA, in 2010, and 12 months later, in 2011. The values did not present normal distribution. The medians (Q1; Q3) were $0.50 \mu \mathrm{g} / \mathrm{L}(0.31 ; 0.91)$ and $0.09 \mu \mathrm{g} / \mathrm{L}(0.04 ; 0.13)$ for 2010 and 2011 serum samples, respectively. Indeed, values were significantly lower in the second collection $(p<0.0001)$, regardless as to whether the analysis included all the data or only the paired data.

Fig. 4 shows the values of lead in saliva for samples collected in Santo Amaro, BA in 2010 and 2011. The values did not show normal distribution. The medians (Q1; Q3) were $5.00 \mu \mathrm{g} / \mathrm{L}(1.00 ; 12.5)$

Table 1

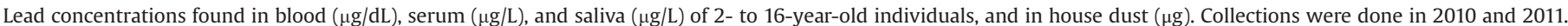
Ribeirão Preto, SP, 2012

\begin{tabular}{|c|c|c|c|c|c|c|c|c|c|c|}
\hline & $\begin{array}{l}\text { Blood } \\
2010\end{array}$ & $\begin{array}{l}\text { Blood } \\
2011\end{array}$ & $\begin{array}{l}\text { Serum } \\
2010\end{array}$ & $\begin{array}{l}\text { Serum } \\
2011\end{array}$ & $\begin{array}{l}\text { Saliva } \\
2010\end{array}$ & $\begin{array}{l}\text { Saliva } \\
2011\end{array}$ & $\begin{array}{l}\text { Highest Pb value } \\
\text { in Dust } 2010\end{array}$ & $\begin{array}{l}\text { Highest Pb value } \\
\text { in Dust } 2011\end{array}$ & $\begin{array}{l}\text { Mean Pb in } \\
\text { Dust } 2010\end{array}$ & $\begin{array}{l}\text { Mean Pb in } \\
\text { Dust } 2011\end{array}$ \\
\hline$n$ & 99 & 67 & 92 & 50 & 61 & 61 & 82 & 64 & 82 & 64 \\
\hline Minimum & 1.58 & $<1.0$ & $<0.01$ & 0.04 & $<0.04$ & $<0.04$ & 0.69 & 0.06 & 0.48 & 0.04 \\
\hline Q1 & 2.85 & 1.0 & 0.25 & 0.04 & 1.00 & 0.1 & 4.64 & 0.96 & 3.55 & 0.68 \\
\hline Median & 3.45 & 1.67 & 0.51 & 0.09 & 5.00 & 0.82 & 7.9 & 1.85 & 6.42 & 1.44 \\
\hline Q3 & 4.79 & 2.70 & 0.91 & 0.13 & 12.5 & 4.0 & 15.10 & 3.17 & 10.72 & 2.96 \\
\hline Maximum & 13.04 & 11.23 & 1.82 & 0.66 & 52.0 & 40.0 & 40.79 & 36.01 & 26.59 & 27.81 \\
\hline Mean & 3.94 & 2.10 & 0.67 & 0.12 & 9.6 & 3.52 & 10.88 & 3.76 & 8.06 & 2.58 \\
\hline Standard Deviation & 1.79 & 1.49 & 0.57 & 0.14 & 11.82 & 7.13 & 8.2 & 6.2 & 5.5 & 4.0 \\
\hline Normal Distribution & No & Yes & No & No & No & No & No & No & No & No \\
\hline
\end{tabular}




\section{$\mathrm{Pb}$ in plasma samples collected in Santo Amaro, BA, in 2010 and 2011}

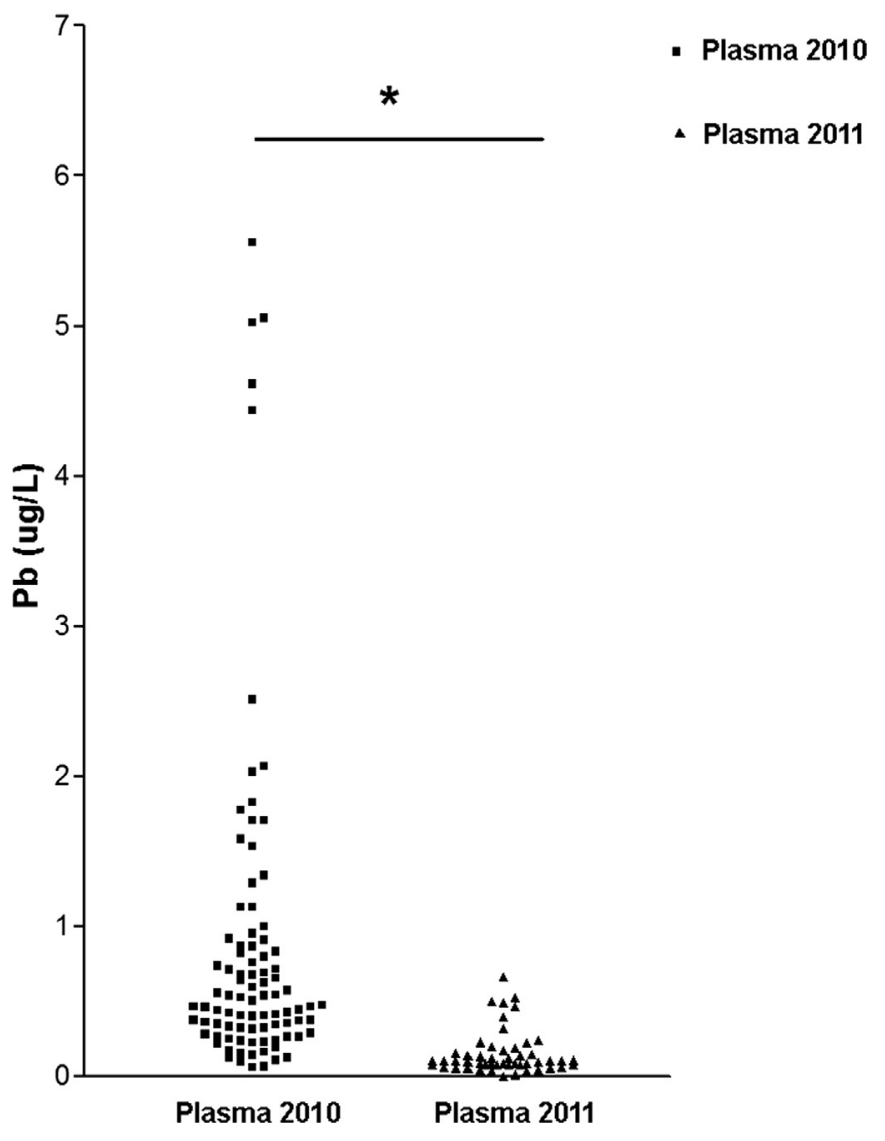

Fig. 3. Lead in serum of samples collected from children aged 2-16 living in Santo Amaro, BA, in $2010(n=92)$ and 1 year later, in $2011(n=50) .{ }^{*} p<0.0001$, MannWhitney test.

for 2010 , and $0.82 \mu \mathrm{g} / \mathrm{L}(0.1 ; 0.4)$ for 2011 . Also the results of lead in saliva were lower in the second year $(p<0.001)$.

Comparisons shown in Figs. 2-5 were analyzed using paired analysis, but unpaired analysis also resulted in significant differences.

We determined lead in wipes that were used to obtain dust from a $0.3 \times 0.3 \mathrm{~m}$ square. Lead is expressed as the mass/area, i.e., micrograms per square meter $\left(\mu \mathrm{g} / \mathrm{m}^{2}\right)$. The lead measured in dust confirmed the trend verified in the other analyses regarding the decrease in lead concentrations on going from 2010 to 2011. Fig. 5 brings the results for lead in house dust (mean of three wipes collected in separate rooms of the house). Lower lead values emerged in 2011 as compared with 2010 data $(p<0.0001)$. Like most variables in this study, the values did not follow a Gaussian distribution; the medians (Q1; Q3, and $n$ ) for were 87.78 (51.56; $167.78, n=82)$ and $20.56(10.67 ; 35.22, n=64)$ for 2010 and 2011 , respectively.

Table 2 summarizes the correlation values. Only BLLs in 2010 and 2011 (shown in Fig. 6) and in the house dust in 2010 and 2011 correlated significantly ( $p=0.0001$ for both correlations). Those 2 correlations remained significant after Bonferroni correction ( 0.05 divided by 18 comparisons, $p=0.0031$ ).

It is noteworthy that BLL correlation relied on 62 pairs; that is, we were able to obtain blood samples from the same 62 participants in 2010 and 2011 (Spearman's $r=0.56$ and $p<0.0001$ ). The one sample that showed BLL above $10 \mu \mathrm{g} / \mathrm{dL}$ did not affect the

\section{Lead in house dust (ug)}

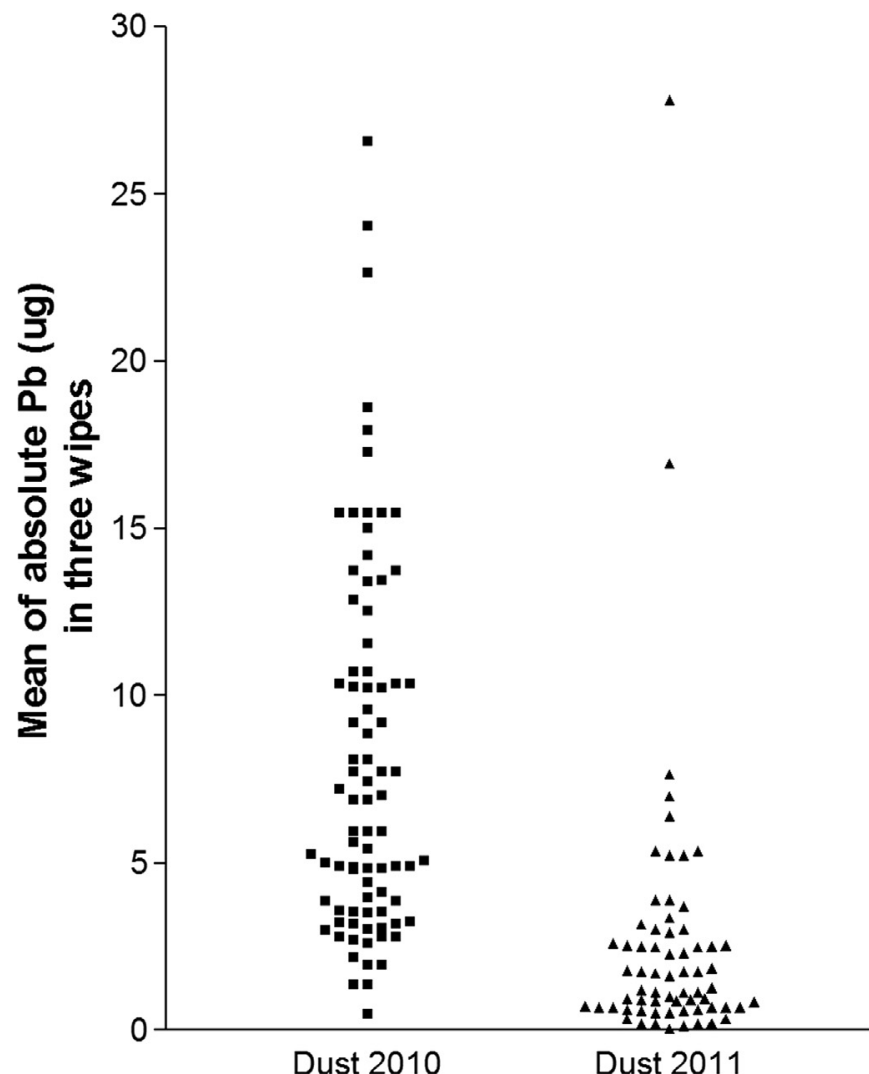

Fig. 4. Lead in saliva of samples collected from children aged 2-16 living in Santo Amaro, BA, in $2010(n=61)$ and 1 year later, in 2011 ( $n=61) .{ }^{*} p<0.0001$, MannWhitney test.

results appreciably: without these two values, we achieved Spearman's $r=0.53$ and the $\mathrm{p}$ value was the same.

In 2011, the mean age of the children enrolled in this study was 9 years and 9 months.

For all the types of samples used in this study, we collected a reduced number of samples in the second year, this is particularly true for blood. This happened because some parents/guardians failed to see that a second collection was important, or because the participant moved from the study site.

\section{Discussion}

Data from this study showed that lead levels decreased from 2010 to 2011 in the city of Santo Amaro, BA, as attested by the different biomarkers tested here. For this investigation, we determined lead in whole blood, serum, saliva, and house dust. The last sample did not consist of a biological sample collected from the children, so it served to corroborate the trend toward lower lead concentrations on going from the year 2010 to 2011. If it were not for the results obtained with the dust samples, we would not be sure whether the lower lead concentrations were related to the children's growth or to a real change in the environment. This indicates that paving the Rui Barbosa Avenue contributed to mitigating the impact of the contamination.

Santo Amaro, BA, is a town where former employees of the lead smelting plant still live. Some publications (Carvalho et al., 2003; Machado et al., 2004; Andrade and Moraes, 2013) and many talks in the city have dealt with the risk of undue exposure to high lead levels due to the lead-contaminated rejected material (slag form of 


\section{Pb-Blood 2010 x Pb-Blood 2011}

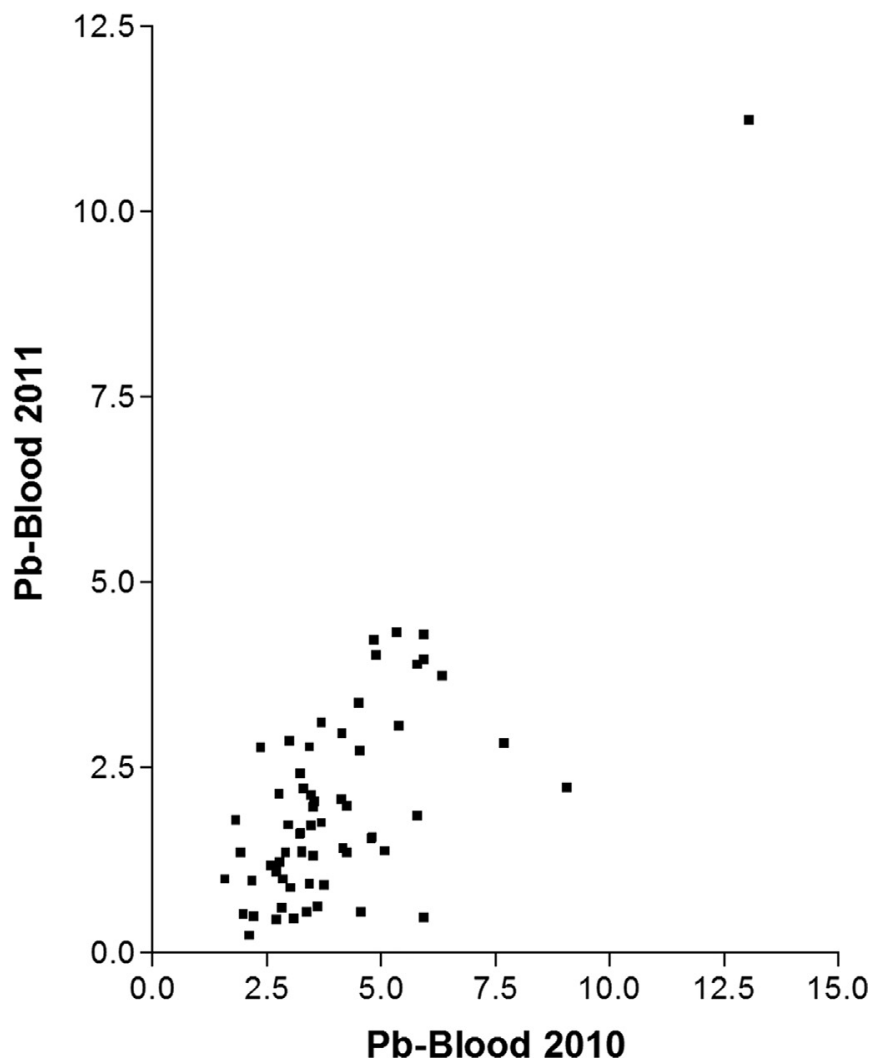

Fig. 5. Mean of lead in dust obtained with wipes in 3 rooms of the houses. Lead content is expressed as the mass/area, i.e., micrograms per square meter $\left(\mu \mathrm{g} / \mathrm{m}^{2}\right)$. The house areas were the living room, the kitchen and the child's bedroom. Collections were done in October 2010 ( $n=82$ houses) and October $2011(n=64$ houses). ${ }^{*} p<0.0001$ for the decrease in lead found in 2010 versus 2011.

the refining process) left uncovered for decades on the ground at the plant site and encapsulated only a decade ago (Machado et al., 2013; Magna et al., 2013). To make matters worse, the municipality authorities used the rejected material contaminated with $\sim 3 \%$ lead to pave the streets on many occasions in the past.

The results presented here are consistent with decreased exposure to lead in the tested population. Since the shutdown of the

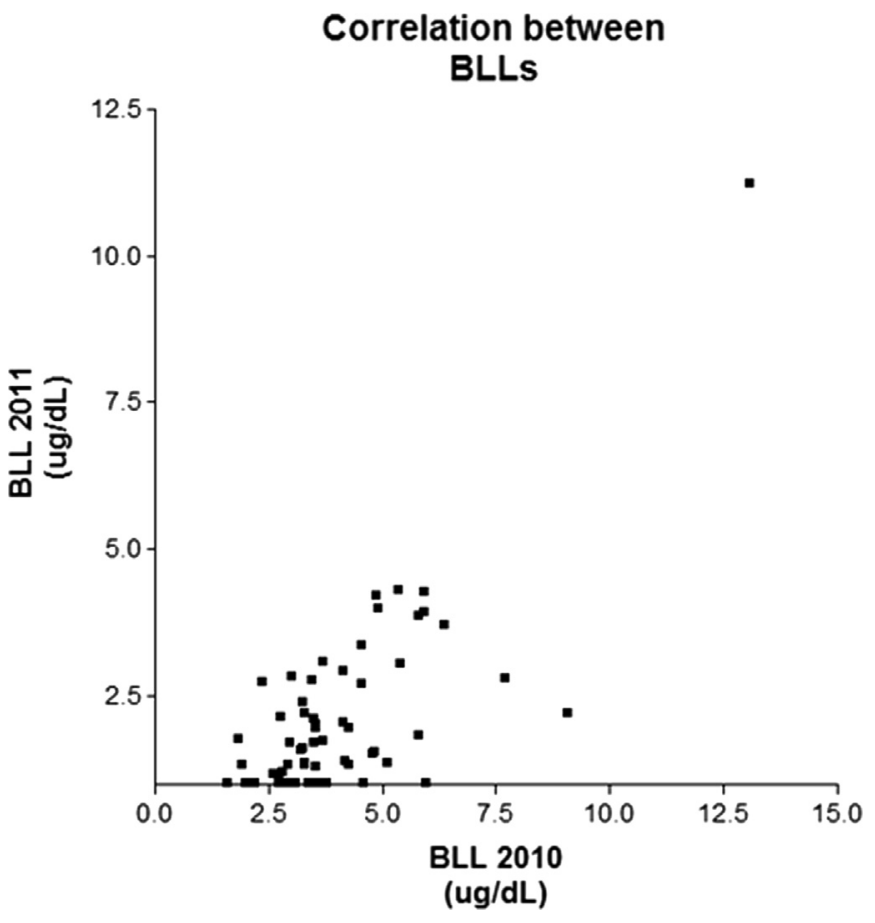

Fig. 6. Correlation between BLLs from children aged 2-16 living in Santo Amaro, $\mathrm{BA}$, in 2010 and 1 year later, in 2011. A moderate significant correlation was found (Spearman's $r=0.55 ; n=62 ; p<0.0001$ ).

plant during the 1990s, consecutive epidemiological studies have reported significantly lower BLL (Blood lead levels) in children, from $59.1 \mu \mathrm{g} / \mathrm{dL}(S D=25)$ in 1985 , during full operation of the refining plant, to $17.1 \mu \mathrm{g} / \mathrm{dL}(\mathrm{SD}=7.3$ ) in 2003,10 years after the end of all plant operations (Carvalho et al., 2003). At the same time that the declining BLLs indicate that exposure has diminished, and that not so many children have BLL above $5 \mu \mathrm{g} / \mathrm{dL}$, which is the current definition of elevated BLL proposed for children in the U.S. A. (Binns et al., 2007; ACCLPP-CDC, 2012. Therefore, even though the results suggest a successful outcome, they should motivate the community and health authorities to act aiming to reduce exposure.

Although the median BLL of $3.4 \mu \mathrm{g} / \mathrm{dL}$ in 2010 may be considered higher than reference values produced in a cohort of sixto eight-year-old children from Ribeirao Preto, SP (median: $2.2 \mu \mathrm{g} /$

Tabel 2

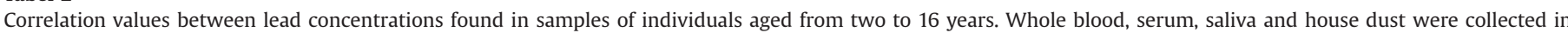
Santo Amaro, BA, in October 2010 and October 2011. Spearman's $r$ is shown. Ribeirao Preto, SP, Brazil, 2014.

\begin{tabular}{|c|c|c|c|c|c|c|c|}
\hline & Blood 2011 & Serum 2010 & Serum 2011 & Saliva 2010 & Saliva 2011 & $\begin{array}{l}\text { Mean Lead in } 3 \text { House Dust samples } \\
2010\end{array}$ & $\begin{array}{l}\text { Mean Lead in } 3 \text { House Dust samples } \\
2011\end{array}$ \\
\hline Blood 2010 & $\begin{array}{l}r=0.56 \\
p<0.0001 \\
n=62\end{array}$ & $\begin{array}{l}\text { n.s. } \\
n=89\end{array}$ & - & $\begin{array}{l}\text { n.s. } \\
n=53\end{array}$ & - & $\begin{array}{l}\text { n.s. } \\
n=81\end{array}$ & - \\
\hline Blood 2011 & & - & $\begin{array}{l}\text { n.s. } \\
n=89\end{array}$ & - & $\begin{array}{l}\text { n.s. } \\
n=57\end{array}$ & - & $\begin{array}{l}\text { n.s. } \\
n=64\end{array}$ \\
\hline Serum 2010 & & & $\begin{array}{l}\text { n.s. } \\
n=42\end{array}$ & $\begin{array}{l}\text { n.s. } \\
n=50\end{array}$ & - & $\begin{array}{l}\text { n.s. } \\
n=78\end{array}$ & - \\
\hline Serum 2011 & & & & - & $\begin{array}{l}\text { n.s. } \\
n=53\end{array}$ & - & $\begin{array}{l}\text { n.s. } \\
n=48\end{array}$ \\
\hline Saliva 2010 & & & & & $\begin{array}{l}\text { n.s. } \\
n=49\end{array}$ & $\begin{array}{l}\text { n.s } \\
n=61\end{array}$ & - \\
\hline Saliva 2011 & & & & & & - & $\begin{array}{l}\text { n.s. } \\
n=57\end{array}$ \\
\hline $\begin{array}{l}\text { Mean House Dust } \\
2010\end{array}$ & & & & & & & $\begin{array}{l}r=0.5 \\
p<0.0001 \\
n=59\end{array}$ \\
\hline
\end{tabular}


dL, $n=444$ ), a city with no known source of undue exposure to lead (Costa de Almeida et al., 2010), the median BLL of $1.72 \mu \mathrm{g} / \mathrm{dL}$ (or the mean of $2.0 \mu \mathrm{g} / \mathrm{dL}$ ) verified in Santo Amaro in 2011 raises little epidemiological concern regarding current general population environmental exposure to lead. The difference between median and mean clearly indicates that a subgroup of children has undergone higher exposure, which actually is reason for concern from the municipality, health authorities, and the community.

The other finding of this study concerns the lead concentrations found in serum and saliva. The lack of correlation of lead in serum with $\mathrm{Pb}$-blood may reflect the fact that serum has higher levels of lead than plasma, although we had not expected this because an earlier study showed a high correlation between lead determined in serum and plasma (Rezende et al., 2010), but the standing time was only 30 minutes. Another reason for the lack of correlation between lead in serum and in blood may be the relatively low blood lead levels in this population, and the narrow range of values. This suggests that serum is of little use as a biomarker for field collections. We were also expecting to find some degree of correlation of lead in saliva and lead in Pb-blood, but this was not found. Saliva contamination with lead from blood cannot be ruled out. Little gingival bleeding was observed (due to gingivitis, although this was not recorded with a specific index). Additionally, as stated by Costa de Almeida et al. (2009a), "lead may be released from the enamel during periods of low $\mathrm{pH}$, and, consequently, increasing the amount of lead in the saliva. This hypothesis deserves study, since in such process children would be re-exposed to the lead accumulated in their enamel (which will be then swallowed and absorbed)". Nonetheless, both serum and saliva still marked the increased exposure to lead in the first year.

Regarding the lack of correlation between Pb-Blood and lead in house dust, our results contrast with those reported by Trepka et al. (1997). These authors investigated a German region historically characterized by non-ferrous mining and metallurgical activities, and verified significant correlation between Pb-Blood in children and lead concentrations in house dust $(r=0.40$; $p=0.0001$ ). Flores-Ramirez et al. (2012) observed the same situation when they compared $\mathrm{Pb}$-Blood and lead in house dust $(r=0.90 ; p<0.001)$. A more consistent collection of dust over time may be necessary to reflect exposure to lead to the same degree that blood does.

Our study revealed that only one child exhibited signs of high exposure to lead (above $10 \mu \mathrm{g} / \mathrm{dL}$ ), a situation that we had already observed in Ribeirao Preto. In the latter city, although most children have low blood lead levels, a minority is not protected from undue lead exposure. In the case of Santo Amaro, authorities had expected even higher levels of lead in blood than the ones we determined. As for Ribeirao Preto, SP, a city with no known source of exposure to lead, circa $5 \%$ of the children have blood lead levels above $5 \mu \mathrm{g} / \mathrm{dL}$, which deserves further investigation. Even though lead contamination is not considered to be a public health problem in Brazil, undue exposure of children to lead can have deleterious effects. Moreover, since 2007, blood lead levels that should prompt public health actions have been decreased from 10 to $5 \mu \mathrm{g} / \mathrm{dL}$ (Binns et al., 2007; ACCLPP-CDC, 2012).

As already mentioned, the diminished lead values verified in Santo Amaro (especially in the second year) suggest that the educational measures were incorporated into the families' habits, as well as some successful outcome. Mass of lead in dust often reflects housekeepoing practices, and therefore the reduction is encouraging. Together, these results showed that paving the streets, and launching educational measures to protect the population from exposure to dust constituted effective measures. Actually, the results indicated that authorities and community have the key to further decrease the exposure to lead revealed by BLLs.

A limitation of this study is the fact that we concentrated on using correlations and simple comparisons. Multivariate analyses could have been used. However, in our view, the results presented are robust, and may contribute for future work on lead in our country. The few correlations found make sense from a biological and toxicological point of view, and may therefore indicate important aspects for further studies for those aiming at comparing lead in multiple fluids and in dust.

Unfortunately, despite these promising data, the lead already stored in the bones of the investigated children may reenter the circulation during intense growth periods. In other words, in the children that participated in this study, a growing population, BLLs may change and even increase, so regular and continuous BLL monitoring is mandatory. Based on results from primary teeth collected in the city of Santo Amaro in the years 2007-2009, we have data showing that $8 \%$ of the teeth collected in the different parts of the city have high levels of lead (when compared with the distribution of hundreds of teeth that we have determined over the years, with particular interest in the outer enamel) (Guerra, 2010). This clearly demonstrates that biomarkers that mimic bone reveal high levels of lead, which is not an unexpected finding at all. Indeed, the excellence of primary teeth as markers of past exposure to lead is well known when lead levels in dentine are used with standard analytical techniques for lead determination. Dentine lead levels were crucial to determine that chronic exposure to lead had negative effects on school performance of children (Needleman et al., 1979). Nonetheless, we have been working with lead determination in the superficial enamel in the past decade, and the outer enamel is also a good marker of past (probably cumulative) exposure to lead (Gomes et al., 2004; Costa de Almeida et al., 2007; de Almeida et al., 2008; Costa de Almeida et al., 2009b; Costa de Almeida et al., 2011; Molina et al., 2011), and it seems that extreme care has to be taken regarding the selection of the methodologies to determine lead, since even extra sensitive methodologies like synchrotron-radiation induced X-ray fluorescence is not in the least comparable to the excellency of the determination of lead in solutions of superficial enamel obtained by successive acid etches and measured by GF-AAS or ICP-MS, where lead is highly concentrated (de Souza Guerra et al., 2014).

Results shown in this study suggest that measures such as paving contaminated soil and educational campaigns succeeded in decreasing exposure to lead in the target community, as attested by the lower BLLs found in the studied population. However, it will only be possible to accurately assess the true toxicological risk connected with exposure to lead of children that live and grow in Santo Amaro if a long-term biomarker of lead body burden is available. Nowadays, bone constitutes the best of such markers (Barbosa et al., 2005), but such analyses are only done for research and are not yet used for surveillance purposes. We are currently working on the analysis of dentin and enamel collected from these children, to gain further insight into the degree of exposure of this population to lead. We are seeking to correlate such data with lead body burden calculated from several BLL data collected over the years, which should provide the basis for correct risk assessment within this community as well as for deeper understanding of the biomarkers of exposure.

\section{Conclusions}

Concerning the area of Santo Amaro, BA, Brazil, located near a former lead smelting plant, as well as homes localized on Rui Barbosa Avenue, this study showed that lead concentrations found in the participants' blood and, serum and saliva decreased from 2010 to 2011; lead amount in house dust samples also diminished. The structural measure of paving streets, as well as the educational measures to reduce exposure to the contaminated dust are the 
likely explanation for the observed reduction. While BLLs from the two different time points correlated significantly, the same being true for the dust samples collected in 2010 and 2011, no such correlations occurred for serum and saliva samples. No significant correlations were found between different samples (blood, serum, saliva, and house dust), either.

\section{Funding sources and Ethical approvals}

This study was financially supported by The (Brazilian) Research Council (Conselho Nacional de Desenvolvimento Científico e Tecnológico, CNPq, Brasilia, Brazil) Grant 477641/2009-1 (Main Investigator: Dr. Miriam F. C. Machado). The State of São Paulo Research Foundation (Fundação de Amparo à Pesquisa do Estado de São Paulo, FAPESP, São Paulo, Brazil) Grant 2008/57491-8 (Main Investigator: Dr. Raquel F. Gerlach). Carolina S. Guerra was supported by a PhD program grant (salary) from FAPESP. Gustavo A. M. Magna was supported by a PhD program fellowships from CAPES (Brasilia, Brazil).This study was approved by: The Dental School of Ribeirao Preto / University of Sao Paulo Review Board. The Dental School of Ribeirao Preto / University of Sao Paulo Review Board. Protocol number: 2009.1.973.58.0 corresponding to CAAE n. 0073.0.138.000-09. Protocol number: 2009.1.973.58.0 corresponding to CAAE n. 0073.0.138.000-09. Approval date: October 21st, 2009. The Gonçalo Moniz Research Center / Oswaldo Cruz Foundation (FIOCRUZ), Salvador, BA. Protocol number: 324. Review number 217/2010. Approval date: April 13th, 2010.

\section{Acknowledgements}

This study was supported by the (Brazilian) National Research Council, Conselho Nacional de Pesquisa (CNPq), Brasilia, DF, Brazil, and the State of Sao Paulo Research Foundation (FAPESP), Sao Paulo, SP, Brazil. We acknowledge the help of the health authorities from Santo Amaro, BA, and from the State of Bahia in Salvador, BA, with which this study was discussed in detail.

\section{References}

ACCLPP-CDC (2012). Low level lead exposure harms children: a renewed call for primary prevention Atlanta: CDCP.

Andrade, M.F., Moraes, L.R.S., 2013. Lead contamination in Santo Amaro defies decades of research and delayed reaction on the part of the public authorities. Ambient \& Society $16,63-80$.

Anjos, J.A.S.A., 1998. Remediation strategies for a contaminated site by heavy metals. Case study. MSc dissertation. Universidade de São Paulo.

Barbosa Jr., F., Tanus-Santos, J.E., Gerlach, R.F., Parsons, P.J., 2005. A critical review of biomarkers used for monitoring human exposure to lead: advantages, limitations, and future needs. Environ. Health Perspect. 113, 1669-1674.

Binns, H.J., Campbell, C., Brown, M.J., 2007. Centers for disease control and prevention advisory committee on childhood lead poisoning prevention. Interpreting and managing blood lead levels of less than $10 \mu \mathrm{g} / \mathrm{dL}$ in children and reducing childhood exposure to lead: recommendations of the Centers for Disease Control and Prevention Advisory Committee on Childhood Lead Poisoning Prevention. Pediatrics 120, e1285-e1298.

BRASIL 2010. 〈http://cidades.ibge.gov.br/xtras/perfil.php?codmun $=292860\rangle$ (accessed May 2014)

Carvalho, F.M., Silvany-Neto, A.M., Tavares, T.M., Costa, A.C.A., Chaves, C.R., Nascimento, L.D., Reis, M.A., 2003. Chumbo no Sangue de Crianças e Passivo Ambiental de uma Fundição de Chumbo no Brasil. Bull. Pan. Am. Sanit. Bull. 13, 11-14 (In Portuguese).

Costa de Almeida, G.R., Pereira Saraiva, M. da C., Barbosa Jr., F., Krug, F.J., Cury, J.A., Rosário de Sousa, M. da L., Rabelo Buzalaf, M.A., Gerlach, R.F., 2007. Lead contents in the surface enamel of deciduous teeth sampled in vivo from children in uncontaminated and in lead-contaminated areas. Environ. Res. 104, 337-345.

de Almeida, G.R., de Souza Guerra, C., Tanus-Santos, J.E., Barbosa Jr., F., Gerlach, R.F., 2008. A plateau detected in lead accumulation in subsurface deciduous enamel from individuals exposed to lead may be useful to identify children and regions exposed to higher levels of lead. Environ. Res. 107, 264-270. http://dx.doi.org/ 10.1016/j.envres.2008.01.002.

Costa de Almeida, G.R., De Freitas, C.U., Barbosa Jr., F., Tanus-Santos, J.E., Gerlach, R. F., 2009a. Lead in saliva from lead-exposed and unexposed children. Sci. Total Environ. 407, 1547-1550. http://dx.doi.org/10.1016/j.scitotenv.2008.10.058.

Costa de Almeida, G.R., Molina, G.F., Meschiari, C.A., Barbosa de Sousa, F., Gerlach, R. F., 2009b. Analysis of enamel microbiopsies in shed primary teeth by Scanning Electron Microscopy (SEM) and Polarizing Microscopy (PM). Sci. Total Environ. 407, 5169-5175. http://dx.doi.org/10.1016/j.scitotenv.2009.04.044.

Costa de Almeida, G.R., Tavares, C.F.F., De Souza, A.M., De Sousa, T.S., Funayama, C.A R., Barbosa Jr., F., Tanus-Santos, J.E., Gerlach, R.F., 2010. Whole blood, serum, and saliva lead concentrations in 6- to 8-year-old children. Sci.Total Environ. 408, 1551-1556. http://dx.doi.org/10.1016/j.scitotenv.2009.12.034.

Costa de Almeida, G.R., de Sousa Guerra, C., de Angelo Souza Leite, G., Antonio, R.C., Barbosa Jr., F., Tanus-Santos, J.E., Gerlach, R.F., 2011. Lead contents in the surface enamel of primary and permanent teeth, whole blood, serum, and saliva of 6 to 8-year-old children. Sci. Total Environ. 409, 1799-1805. http://dx.doi.org/ 10.1016/j.scitotenv.2011.01.004.

De Freitas, U.C., De Capitani, E.M., Gouveia, N., Simonetti, M.H., Paula, E., Silva, M.R. Kira, C.S., Sakuma, A.M., Carvalho, M.F.H., Duran, M.C., Tiglea, P., De Abreu, M.H. 2007. Lead exposure in a urban community: Investigation of risk factors and assement of the impact of lead abatement measures. Environ. Res. 103, 338-344.

de Souza-Guerra, C., Barroso, R.C., de Almeida, A.P., Peixoto, I.T., Moreira, S., de Sousa, F.B., Gerlach, R.F., 2014. Anatomical variations in primary teeth microelements with known differences in lead content by micro-Synchrotron Radiation X-Ray Fluorescence ( $\mu$-SRXRF)-A preliminary study. J. Trace Elem. Med Biol. 28, 186-193. http://dx.doi.org/10.1016/j.jtemb.2014.01.007.

Denworth, L., 2009. Toxic Truth: a Scientist, a Doctor, and the Battle over Lead. Beacon Press Books, Boston MA, USA, p. 230.

Flores-Ramirez, R., Rico-Escobar, E., Nuñez-Monreal, J.E., García-Nieto, E., Carrizales, L., Ilizaliturri-Hernández, C., Díaz-Barriga, F., 2012. Exposición al plomo en sitios contaminados. Salúd Publica de Mexico 54, 383-392.

Gomes, V.E., Rosário de Sousa, M., da, L., Barbosa Jr., F., Krug, F.J., Pereira Saraiva, M., da, C., Cury, J.A., Gerlach, R.F., 2004. In vivo studies on lead content of deciduous teeth superficial enamel of preschool children. Sci. Total Environ. 320, 25-35.

Guerra, C.S., 2010. Utilização de dentes decíduos de regiões com diferentes históricos de contaminação ambiental para detecção de grupos de crianças expostas ao chumbo no Brasil. Doctoral dissertation, Universidade Estadual de Campinas-UNICAMP. State University of Campinas, Piracicaba, SP, Brazil.

Machado, S.L., Ribeiro, L.D., Kiperstok, A., Botelho, M.A.B., Carvalho, M.F., 2004. Diagnóstico da contaminação por metais pesados em Santo Amaro-BA (Abstract in english: Diagnostico of contamination by heavy metals in Santo Amaro, BA). Eng Sanit. Ambient 9, 140-151.

Machado, S.L., Rabelo, T.S., Portella, R.B., Carvalho, M.F., Magna, G.A.M., 2013. A study of the routes of contamination by lead and cadmium in Santo Amaro, Brazil. Environ. Technol. 34, 559-571.

Magna, G.A.M., Machado, S.L., Carvalho, M.F., Portella, R.B., 2013. Lead and cadmium detected in plant foods and grasses in Santo Amaro, Bahia [In Portuguese with abstract in English]. Quimica Nova 36, 989-997.

Markowitz, G., Rosner, D., 2013. Lead wars: The politics of science and the fate of America's children. University of California Press, Berkeley and Los Angeles, CA, USA.

Molina, G.F., Costa de Almeida, G.R., de Souza Guerra, C., Cury, J.A., de Almeida, A.P., Barroso, R.C., Gerlach, R.F., 2011. Lead deposition in bovine enamel during a pHcycling regimen simulating the caries process. Caries Res. 45, 469-474. http: //dx.doi.org/10.1159/000330602.

Needleman, H., Gunnoe, C., Leviton, A., Reed, R., Peresie, H., Maher, C., Barrett, P., 1979. Deficits in psychologic and classroom performance of children with elevated dentine lead levels. N. Engl. J. Med. 300, 689-695.

Oliveira, L.B., 2010. Metal interaction forms in atmospheric particulate matter in the town of Santo Amaro /Bahia. MSc dissertation. Universidade Federal da Bahia.

Paoliello, M.M., Capitani, E.M., Cunha, F.G., Matsuo, T., Carvalho, M.F., Sakuma, A., Figueiredo, B.R., 2002. Exposure of Children to Lead and Cadmium from a Mining Area of Brazil. Environ. Res. 88, 120-128.

Paoliello, M.M.B., De Capitani, E.M., 2007. Occupational and environmental human lead exposure in Brazil. Environ. Res. 103, 288-297.

Parsons, J.J., Slavin, W., 1993. A rapid Zeeman graphite furnace atomic absorption spectrometric method for the determination of lead in blood. Spectrochem. Acta 48B, 925-939.

Rabelo, T.S., 2010. A study of the remaining routes of contamination by lead and cádmium in Santo Amaro, BA. MSc dissertation. Universidade Federal da Bahia.

Rezende, V.B., Amaral, J.H., Gerlach, R.F., Barbosa Jr., F., Tanus-Santos, J.E., 2010. Should we measure serum or plasma lead concentrations? J. Trace Elem. Med Biol. 24 (3), 147-151. http://dx.doi.org/10.1016/j.jtemb.2010.01.008, Jul.

Trekpa, M.J., Heinrich, J., Krause, C., Schulz, C., Lippold, U., Meyer, E., Wichman, H.E. 1997. The internal burden of lead among children in a smelter town-a small area analysis. Environ. Res. 72, 118-130.

Warren, C., 2000. Brush with Death: a Social History of Lead Poisoning. The Johns Hopkins University Press, Baltimore, MD, USA.

Yoshinaga, J., Yamasaki, K., Yonemura, A., Ishibashi, Y., Kaido, T., Mizuno, K., Takagi M., Tanaka, A., 2014. Lead and other elements in house dust of Japanese residences - Source of lead and health risks due to metal exposure. Environ. Pollut. 189, 223-228. 